\title{
Service evaluation of the paediatric dental general anaesthesia service in NHS Lothian
}

\author{
Kirstie T.-R. Lau, ${ }^{\star 1}$ Jeyanthi John, ${ }^{2}$ Kenneth A. Eaton ${ }^{3}$ and Alexander J. Keightley ${ }^{4}$
}

\section{Key points}

Dental general anaesthetic rates were around twice as high for children from the most deprived than from the least deprived neighbourhoods.
The current local dental general anaesthesia (DGA) pathway does not ensure that children discharged from secondary care receive active follow-up preventive care.
There are opportunities for more collaboration and research to improve the dental needs of local children and reduce the need for DGAs.

\begin{abstract}
Objective To gain insight into the reasons for children undergoing dental treatment under general anaesthesia in NHS Lothian.

Methods This service evaluation was based on a representative sample size of 294 patients, randomly selected from the 1,236 children seen for dental general anaesthesia (DGA) during 2017 in NHS Lothian. Data on patient and treatment descriptors were collected retrospectively from clinical records and analysed to identify significant correlations.

Results The data indicated paediatric DGAs were mostly provided due to dental caries (88\%, 260/294) and for children from the most deprived areas of Lothian. Most children were referred because they were of a very young age or had needs which precluded treatment under local anaesthesia (LA). Almost every child had teeth extracted under DGA $(99 \%, 290 / 294)$ and a third of children received restorations (33\%, 96/294).

Discussion and conclusion This study highlighted the disproportionate increased risk of dental caries and DGA in children from more deprived backgrounds, despite a nationwide reduction of children with caries experience. There is a need for more holistic, whole-system approaches to reduce child dental caries, with opportunities for collaborative work with local stakeholders to follow-up children who have had DGA. More research is needed locally and nationally to inform the translation of evidence into effective interventions.
\end{abstract}

\section{Background}

Dental caries in children is largely preventable but is among the most prevalent childhood diseases in the UK. ${ }^{1}$ Dental caries can lead to toothache, which is undesirable, particularly in a young child. Toothache may mean sleepless nights for children and parents, affect children's diet and nutrition, and impact on learning. ${ }^{2,3}$ Poor oral health

${ }^{1}$ Senior House Officer, Oral and Maxillofacial Surgery, Torbay Hospital, Newton Road, Torquay, Devon, TQ2 7AA, UK; ${ }^{2}$ Consultant, Dental Public Health, Wessex \& Thames Valley, Public Health England South East, Wellington House, 133-155 Waterloo Road, Lambeth, London, SE1 8UG, UK; ${ }^{3}$ Honorary Professor, University of Kent, Centre for Professional Practice, Compass Centre South, Chatham Maritime, Kent, ME4 4YG, UK; ${ }^{4}$ Consultant, Paediatric Dentistry, Edinburgh Dental Institute, Lauriston Building, Lauriston Place, Edinburgh, EH2 9HA, UK.

${ }^{*}$ Corresponding author: Kirstie Lau

Email address: kirstie.lau@nhs.net

Refereed Paper.

Accepted 24 April 2020

https://doi.org/10.1038/s41415-020-1982-z can also be associated with obesity, diabetes, ${ }^{4}$ and a failure to thrive due to oral pain and difficulties eating. ${ }^{5}$

In Scotland, high levels of child dental caries resulted in the introduction of Childsmile, a national oral health programme. Childsmile adopts a universal approach of toothbrush and toothpaste distribution and supervised tooth brushing, alongside a targeted approach of fluoride varnish applications in schools in the most deprived quintile. ${ }^{6,7}$ National dental inspection programmes indicate that, since Childsmile's implementation, the prevalence of child dental caries has dropped significantly across Scotland. ${ }^{8,9}$ However, inequalities still persist and there remains a cohort of children with high levels of dental treatment need.

Some of these children may require a general anaesthetic (GA) to restore or extract teeth, as they are often young and unable to cooperate with a local anaesthetic procedure. In Scotland during 2015-2016, the single largest reason for elective paediatric hospital admissions was due to dental extractions (excluding orthodontic extractions) (17.4\%). For comparison, the next largest treatment reason for hospital admission was tonsil excision (6.6\%) and chemotherapy or radiotherapy delivery (3.8\%). ${ }^{10}$

GA-associated health risks include a high morbidity rate and potential negative impact on child behaviour and emotional health. ${ }^{11,12}$ There is a clear socioeconomic gradient with children from more deprived groups more likely to experience dental general anaesthesia (DGA), although children from all social backgrounds are affected. ${ }^{13}$ DGA has a significant financial impact, costing approximately $£ 836$ for a single hospital episode. ${ }^{14}$ Research in North West England has indicated that most children managed under DGA miss at least two schooldays, with some missing up to 15 days. $^{3}$

The two NHS Lothian hospitals both use a DGA care pathway based on the Association of Paediatric Anaesthetists' model. ${ }^{10}$ Both restoration and extraction treatments are 
provided for children under DGA in NHS Lothian, alongside local anaesthesia (LA) and sedation, and as part of a multi-modality plan. Some children may have attempted and failed treatment under LA or sedation, and then require internal DGA referral. On completion of the DGA course of treatment, children are discharged to their general dental practitioner (GDP) for continuing preventative care. ${ }^{15}$

This paper reports on an evaluation of children treated by the NHS Lothian DGA service during 2017 to inform service development and gain insight into the factors behind the demand for DGA.

The objectives were to:

1. Establish the profile of children receiving DGA

2. Identify the reasons for referrals provided by referrers

3. Identify the treatments provided under DGA

4. Identify limitations in the DGA service.

\section{Methods}

A retrospective service evaluation of children attending for DGA in NHS Lothian was conducted. A total of 1,236 children aged 16 years and under received elective DGA between 1 January and 31 December 2017. A power calculation indicated that 294 randomly selected records would be needed to achieve a statistically representative sample at the $95 \%$ confidence level. Ethics approval was obtained from University of Kent Centre for Professional Practice and consent from Edinburgh Dental Institute Research \& Development Directorate.

A list of all paediatric patients attending for an elective and emergency DGA during 2017 at the two Lothian hospitals, Royal Hospital for Sick Children, City of Edinburgh (RHSC) and St John's Hospital, West Lothian (SJH), was obtained. Each name was assigned a study number in chronological order. The 294 patients in the study were selected by matching a series of randomly generated numbers. Their DGA date and Community Health Index (CHI) number were identified from the theatre list, enabling linking to electronic dental records on Software of Excellence Health version 3.12.1 and Carestream R4 Clinical+ version 6.5.1 software programs used to record clinical dental activity. Data for these patients were retrospectively collected from patients' clinical records. These included age at the time of their DGA, gender, postcode, reason for DGA, treatment provided under DGA,
Table 1 Characteristics of referrals

\begin{tabular}{l|l|l|l} 
Age (years) & $\begin{array}{l}\text { Number of those with } \\
\text { additional needs (\%) }\end{array}$ & $\begin{array}{l}\text { Number of those without } \\
\text { additional needs (\%) }\end{array}$ & Total (\%) \\
\hline $0-4$ & 3 & 59 & $62(21)$ \\
\hline $5-10$ & 28 & 177 & $205(70)$ \\
\hline$>10$ & 7 & 20 & $27(9)$ \\
\hline Total & $\mathbf{3 8 ( 1 3 )}$ & $\mathbf{2 5 6 ( 8 7 )}$ & $\mathbf{2 9 4}(\mathbf{1 0 0})$ \\
\hline
\end{tabular}

\section{Fig. 1 Comparison of deprivation between DGA and local cohorts}

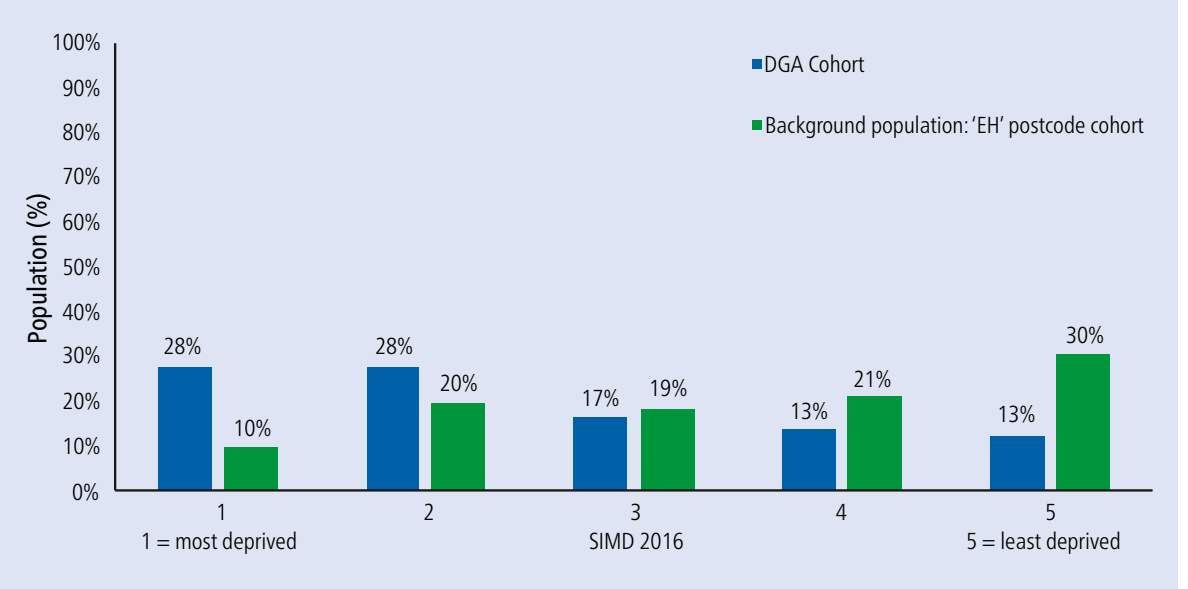

significant recorded medical history, provision of preventive interventions within the overall course of treatment and total number of appointments attended.

Data collection and analysis were conducted on Microsoft Excel 2013 and IBM SPSS Statistics Version 25 for Windows. In line with General Data Protection Regulation 2016/679, only the lead investigator had access to patient identifiable information, which was kept separate from the data capture forms. Patient data were anonymised, encrypted and stored electronically on a secure network for analysis.

\section{Results}

The study sample consisted of 294 children with equal numbers of males and females. Most children were aged 5-10 years old (Table 1).

Children with a record of compromising medical conditions were identified as 'additional needs' and separated from the general cohort. A total of 38 children from the whole cohort $(13 \%, 38 / 294)$ were identified with additional needs. These included developmental disorders (eg autism spectrum, learning disability), behavioural disorders (eg attention deficient disorder) and physical disabilities (eg cerebral palsy, global development disorder). This group also included children who had additional medical conditions complicating their dental care (eg neurofibromatosis, type 1 diabetes, haemophilia carrier and liver transplant recipient).

Figure 1 shows relative deprivation, based on postcode area, for the general population in Lothian compared to the children included in the DGA sample. This illustrates, relative to the background population, that there is overrepresentation of children living in postcodes from the two most deprived quintiles and also under-representation within the DGA sample of children residing in the two least deprived quintiles.

\section{Diagnosis at time of wait-listing for DGA service}

Diagnoses were made in the assessment clinic, with the most frequent being dental caries. There were often multiple other dental diagnoses included within each referral to the DGA service, but for the purposes of this investigation, the diagnosis of caries took precedence over all other diagnoses.

Children were wait-listed for DGA with the following primary diagnoses:

- Dental caries $(260 / 294,88 \%)$

- Surgical removal of ectopic or supernumerary teeth $(17 / 294,6 \%)$ 
Table 2 Reasons given for DGA referral

\begin{tabular}{l|l|l|l} 
Reason & $\begin{array}{l}\text { With additional } \\
\text { needs }\end{array}$ & $\begin{array}{l}\text { Without } \\
\text { additional needs }\end{array}$ & $\begin{array}{l}\text { Number of } \\
\text { children (\%) }\end{array}$ \\
\hline High number of extractions required & 14 & 164 & $178(61 \%)$ \\
\hline Unable to cooperate with LA procedure & 16 & 129 & $145(49 \%)$ \\
\hline Young age & 3 & 58 & $61(21 \%)$ \\
\hline Failed LA/inhalation sedation & 1 & 45 & $46(16 \%)$ \\
\hline Surgical procedure & 1 & 41 & $42(14 \%)$ \\
\hline Medical history & 38 & 0 & $38(13 \%)$ \\
\hline
\end{tabular}

- Molar-incisor hypomineralisation (MIH) (10/294, 3\%)

- Dental trauma (7/294, 2\%).

\section{Reasons for providing treatment under} DGA

Reasons for providing treatment to children in the DGA cohort are listed in Table 2. Multiple reasons were listed by clinicians and it was not possible to determine whether, or which of, these reasons were most important. The data were, therefore, treated as descriptors of the referrals.

Separating the children with caries $(\mathrm{n}=260)$ from the DGA cohort $(\mathrm{n}=294), 35(35 / 260$, $13 \%)$ had additional needs. A total of 46 children $(46 / 60,16 \%)$ had attempted treatment under LA and/or inhalation sedation in the community or hospital service before their internal DGA referral.

\section{Treatment provided under DGA}

Almost all children $(290 / 294,99 \%)$ had teeth extracted, including primary, secondary and/or supernumerary teeth, with a third of children (96/294, 33\%) receiving restorations. Out of those with caries $(260 / 294,88 \%)$, most required extraction of multiple teeth (Table 3 ).

Most restorations provided were for primary teeth and included placement of fillings and preformed metal crowns. Fissure sealants were counted as restorations and were mostly placed on secondary teeth. Children without additional needs had more teeth extracted and a greater number of primary teeth needing restorations than children with additional needs, who in contrast generally received restorations for secondary teeth.

\section{Discussion}

This study reviewed the NHS Lothian DGA service for reasons resulting in demand for DGA services using descriptive data on a representative cohort of Lothian children in 2017. Like many services across the UK, Lothian is experiencing increased numbers of children requiring treatment under DGA. Results from this study found that the main reason for this is dental caries in children from the most deprived backgrounds. Over the past decade, Childsmile has provided oral health promotion, with a focus on highrisk children across Scotland, including in Lothian. ${ }^{6}$ While epidemiological survey evidence indicates a reduction in child caries rates, ${ }^{7,8}$ this does not appear to be translating into a reduced demand for DGA services in the Lothian area. ${ }^{9}$

The present arrangement in Lothian's secondary care actively follows up children referred to the service who do not present for treatment via the local 'was not brought' pathway ${ }^{16}$ and provides discharge summaries on treatment completion requesting follow-up care. However, once a child is discharged from secondary care, there is no system in place to confirm continuation of this pathway in primary care, nor is there direct accessible information of their previous interactions with primary care before their referral. This interface is a potential vulnerability within the system and local collaborative working is needed to develop a more robust system to proactively follow-up children discharged after DGA. Implementation of a coordinated and accessible interface for the wider health and social care system, including primary care, secondary care and community Childsmile teams, could improve the existing system and join ongoing secondary care research with primary care.

Combining information from across health and social systems could aid identification of local communities at greatest risk, and help gain media interest and political support, which could support mobilisation of local resources to address child dental inequalities. For instance, appropriate data linkage of GDP participation data, Childsmile activity data and child DGA data from secondary care could allow for proactive targeting by health and social services to enable active follow-up of children discharged after DGA. By sharing this information, health boards may also be able to identify practices of specific geographic areas which could benefit from additional preventative interventions. However, to successfully set up such a system, careful planning is required to avoid inappropriate information sharing and breach of personal privacy.

There are a number of evidence-based interventions to prevent dental caries, along with clinical interventions to prevent or detect and treat caries at an earlier stage when DGA may be avoidable. ${ }^{3,17}$ However, similar to many areas of healthcare, the effective translation of this evidence into routine practice is challenging, especially due to the numerous determinants influencing health behaviour. ${ }^{17,18,19}$ The development of

Table 3 Treatment provided under DGA for management of dental caries

\begin{tabular}{|c|c|c|c|c|c|c|c|}
\hline \multirow{2}{*}{$\begin{array}{l}\text { Additional } \\
\text { needs }\end{array}$} & \multirow{2}{*}{$\begin{array}{l}\text { Number of children } \\
\text { with dental caries }\end{array}$} & \multirow{2}{*}{$\begin{array}{l}\text { Number of children } \\
\text { who had teeth } \\
\text { extracted (\%) }\end{array}$} & \multicolumn{2}{|c|}{ Number of teeth extracted } & \multirow{2}{*}{$\begin{array}{l}\text { Number of children who } \\
\text { had teeth restored (\%) }\end{array}$} & \multicolumn{2}{|c|}{ Number of teeth restored } \\
\hline & & & Primary & Secondary & & Primary & Secondary \\
\hline With & 35 & $33(94)$ & 209 & 36 & $20(57)$ & 15 & 88 \\
\hline Without & 225 & $225(100)$ & 1398 & 124 & $67(30)$ & 152 & 42 \\
\hline Total & 260 & $258(99)$ & 1607 & 160 & $87(33)$ & 167 & 130 \\
\hline
\end{tabular}


dental caries is multifactorial and it generally takes a number of years for the disease to reach the extent that treatment by DGA is necessary. ${ }^{20,21,22}$ Given that prevention requires consistent delivery over a long-term frame to be effective, ${ }^{3,23}$ ongoing prevention starting early in life is essential. However, the context of a child's life and the decisions made by the adults around them have a major influence on whether they develop dental caries. Interventions need to be holistic and take into account families' lives, culture and priorities, as well as start early in a child's life, to have an impact. Alongside Childsmile in Scotland, ${ }^{5}$ government measures are in place to address child obesity and also child dental caries, such as the 2018 sugar tax levy ${ }^{24}$ and the strategy for 'A Healthier Future. ${ }^{25}$ By building on these existing measures, and engaging with the advertising industry to promote healthier food choices and restrict promotion of less healthy foods, the population can make better food choices, especially older children who purchase their meals outside of school during lunchtime.

At the time of writing, the COVID-19 pandemic means all routine dental care in the UK is suspended. Consequently, this may result in significant demands on the service and increased waiting times once routine clinical practice resumes. At this stage, it is impossible to assess its consequential impact, and it may be necessary for DGA services to reassess their pathways to address demands following the pandemic. While this may present challenges, it could also present opportunities for improved pathways to be developed.

There are a couple of limitations to the comparability of these data. Firstly, the results from this study showed that the main clinical reason for a referral for DGA was because the children needed a significant number of teeth treated and/or were unable to cooperate under LA. It is recognised that, in some parts of the UK, services are only able to offer dental extractions under DGA, with limited or no access to comprehensive restorative treatments under DGA. In Lothian, there are no explicit clinical restrictions for the provision of restorations or extractions under DGA. This ready availability of comprehensive care may result in differences compared to other services, though is unlikely to have impacted the main identified trends.

Although a statistically representative sample of children was sought, the data may not provide an accurate representation of all children who attend for DGA. This includes children with additional needs and medical co-morbidities, who are expected to be of reasonable proportion due to RHSC providing dedicated paediatric outpatient, inpatient and emergency care for Lothian and the surrounding health board areas. This investigation has used a descriptive narrative to present results which can be difficult to compare to other similar studies and also to identify possible opportunities to reduce the DGA risk within local communities.

\section{Conclusion}

This investigation identified that most of the NHS Lothian children included in this study came from the two most socioeconomically deprived quintiles, which is consistent with the available evidence. ${ }^{26,27}$

Maximising benefits of prevention efforts and targeting higher-risk children from more deprived backgrounds is a necessary step of many to improve health outcomes. Improvement of the interface between the DGA service with both primary care and community prevention could improve appropriate follow-up of discharged children and further enhance the targeting of oral health prevention. Collaborative work is essential to ensure these children and their families receive the support needed to prevent development of further dental caries.

Wider prevention approaches across the whole health and social system, and starting early in life, would support all children at increased risk. NHS Lothian DGA data from this study and ongoing work would be useful in identifying communities for targeted efforts and gathering support for mobilising resources. Further research should focus on developing and testing coordinated interventions which involve the whole system and are effective within the Lothian population.

\section{Conflict of interest}

The authors are unaware of any conflicts of interest.

\section{Acknowledgements}

We thank Stephen Turner, Honorary Senior Lecturer and Senior Researcher at Edinburgh Dental Institute, for providing statistical support. Ethics statement: this study was approved by the Research and Development directorate of NHS Lothian and the ethics committee of the Centre for Professional Practice, University of Kent. Patients' permission was not applicable.

\section{Author contributions}

Kirstie TR. Lau: co-planned the study, collected and analysed the data, and wrote the paper; Jeyanthi John: supported reassessment of data and edited the paper; Kenneth Eaton: co-planned the study including ethics application and edited the paper; Alexander Keightley: supervised the study locally, supported reassessment of data and edited the paper.

\section{References}

1. GBD 2016 Disease and Injury Incidence and Prevalence Collaborators. Global, regional, and national incidence, prevalence, and years lived with disability for 328 diseases and injuries for 195 countries, 1990-2016: a systematic analysis for the Global Burden of Disease Study 2016. Lancet 2017: 390: 1211-1259.

2. Sheiham A, James W P. A new understanding of the relationship between sugars, dental caries and fluoride use: Implications for limits on sugar consumption. Public Health Nutr 2014; 7: 2176-2184.

3. Goodwin M, Sanders C, Davies G, Walsh T, Pretty I A. Issues arising following a referral and subsequent wait for extraction under general anaesthetic: impact on children. BMC Oral Health 2015; 15: 3.

4. Lifshitz F, Casavalle P L, Bordoni N, Rodriguez P N, Friedman S M. Oral Health in Children with Obesity or Diabetes Mellitus. Pediatr Endocrinol Rev 2016; 14: 159-167.

5. Sheiham A. Dental caries affects body weight, growth and quality of life in preschool children. Br Dent J 2006; 201: 625-626.

6. Childsmile. About Childsmile. 2011. Available at http://www.child-smile.org.uk/professionals/aboutchildsmile.aspx (accessed October 2019).

7. Macpherson L M D, Ball G E, Brewster L et al. Childsmile: the national child oral health improvement programme in Scotland. Part 1: establishment and development. $\mathrm{Br}$ Dent J 2010; 209: 73-78.

8. Information Services Division Scotland. National Dental Inspection Programme (NDIP) 2018: Report of the 2018 Detailed Inspection Programme of Primary 1 Children and the Basic Inspection of Primary 1 and Primary 7 Children. 2018. Available at https://ndip.scottishdental.org/wp-content/ uploads/2018/10/2018-10-23-NDIP-Report.pdf (accessed October 2019).

9. Information Services Division Scotland. National Dental Inspection Programme (NDIP) 2017: Report of the 2018 Detailed Inspection Programme of Primary 7 Children and the Basic Inspection of Primary 1 and Primary 7 Children. 2017. Available at https://ndip. scottishdental.org/wp-content/uploads/2017/10/ ndip scotland2017-P7.pdf (accessed October 2019).

10. Information Services Division Scotland. Childhood number of procedures and rates by health board of residence. 2016. Available online at https://www. isdscotland.org/Health-Topics/Hospital-Care/ Publications/2016-10-04/Childhood-Number-ofProcedures-and-rates-by-Health-Board-of-ResidenceOct16.xlsx (accessed November 2019).

11. Association of Paediatric Anaesthetists of Great Britain and Ireland. Joint Professional Guidance on the use of general anaesthesia in young children. 2017. Available at https://www apagbi. org.uk/sites/default/files/inline-files/Joint $\% 20$ Professional\%20Guidance $\% 20$ on\%20the $\% 20$ use $\% 20$ of $\% 20$ general\%20anaesthesia\%20in\%20young.pdf (accessed July 2020).

12. Bakri M H, Ismail E A, Ali M S, Elsedfy G O, Sayed T A, Ibrahim A. Behavioral and emotional effects of repeated general anesthesia in young children. Saudi J Anesth 2015; 9: 161-166

13. Mortimore A, Wilkinson R, John J H. Exploring the potential value of using data on dental extractions under general anaesthesia (DGA) to monitor the impact of dental decay in children. Br Dent J 2017; 222: 778-781.

14. Public Health England. Health matters: child dental 
health. 2017. Available at https://www.gov.uk/ government/publications/health-matters-child-dentalhealth/health-matters-child-dental-health (accessed May 2019).

15. Scottish Dental Clinical Effectiveness Programme (SDCEP). Prevention and management of dental caries in children: Dental clinical guidance - second edition. 2018. Available at http://www.sdcep.org.uk/ wp-content/uploads/2018/05/SDCEP-Preventionand-Management-of-Dental-Caries-in-Children-2ndEdition.pdf (accessed November 2018).

16. British Dental Association. Implementing 'Was Not Brought' in your practice. 2019. Available at https:// bda.org/advice/Documents/Was\%20Not\%20 Brought \%20implementation\%20guide\%20AW.pdf (accessed November 2019).

17. Freudenberg N. From lifestyle to social determinants: new directions for community health promotion for community health promotion research and practice. 2007. Available at https://www.cdc.gov/pcd/ issues/2007/jul/06_0194.htm (accessed April 2020).
18. Martino S. Oral health behavioral and social intervention research concepts and methods. J Public Health Dent 2011; 71: S2-S6.

19. Denton M, Prus $S$, Walters V. Gender differences in health: a Canadian study of the psychosocial, structural and behavioural determinants of health. Soc Sci and Med 2004; 58: 2585-2600

20. Scottish Intercollegiate Guidelines Network. Dental interventions to prevent caries in children. 2014. Available a https://www.sign.ac.uk/assets/sign138.pdf (accessed March 2020).

21. Brabner D, Downer M C, Moles D R, Naylor M N. Initial caries attack and average progression rates in 12-year old Isle of Wight children. Comm Dent Health 1995; 12: 190-193.

22. Hall-Scullin E, Whitehead H, Milsom K, Tickle M, Su TL, Walsh T. Longitudinal Study of Caries Development from Childhood to Adolescence. J Dent Res 2017; 96: 762-767.

23. Public Health England. Delivering Better Oral Health an evidence-based toolkit for prevention. 2017.
Available online at https://www.gov.uk/government/ publications/delivering-better-oral-health-anevidence-based-toolkit-for-prevention (accessed March 2020).

24. HM Revenue \& Customs. Soft Drinks Industry Levy. 2016. Available at https://www.gov.uk/government/ publications/soft-drinks-industry-levy/soft-drinksindustry-levy (accessed March 2020).

25. Scottish Government. A Healthier Future: Scotland's diet and healthy weight delivery plan. 2018. Available online at https://www.gov.scot/publications/healthierfuture-scotlands-diet-healthy-weight-delivery-plan/ (accessed March 2020)

26. Masood M, Mnatzaganian G, Baker S R. Inequalities in dental caries in children within the UK: Have there been changes over time? Comm Dent Oral Epidemiol 2019; 47: 71-77.

27. Levin K A, Davies C A, Topping G V, Assaf A V, Pitts $\mathrm{N} \mathrm{B}$. Inequalities in dental caries of 5yearold children in Scotland, 1993-2003. Eur J Public Health 2009; 19: 337-342. 